\title{
Risk control of groundwater exploitation for Zhangye basin in the middle reaches of Heihe River basin, China
}

\author{
XIANG GUOSHENG ${ }^{1,2}$, QIAN JU ${ }^{1,2}$, WANG SHUIXIAN ${ }^{1,2}$, LIU QIN ${ }^{1}$, LIU FEN ${ }^{1} \&$ \\ WAN LIU ${ }^{1}$ \\ 1 College of Resources and Environmental Sciences, Lanzhou University, Lanzhou 730000, Gansu, China \\ qianju@lzu.edu.cn \\ 2 Cold and Arid Regions Environmental and Engineering Research Institute, Chinese Academy of Sciences, Lanzhou \\ 730000, Gansu, China
}

\begin{abstract}
Regulation of the water table is a feasible and effective way to reduce the risk of groundwater exploitation. An index system of groundwater exploitation risk evaluation is developed. The groundwater numerical simulation model is established for Zhangye basin in the middle reaches of Heihe River basin, China. Based on the identification and validation, the model is used for numerical simulation and forecast of groundwater exploitation under the conditions of current and planned development. The results show that the increase of groundwater exploitation amount causes the falling of water table. The increase of groundwater exploitation is $7600 \times 10^{4} \mathrm{~m}^{3}$, which can displace the surface water amount of $10100 \times 10^{4} \mathrm{~m}^{3}$. The annual river runoff can increase $7536 \times 10^{4} \mathrm{~m}^{3}$. It is beneficial to the let-down flow from Zhengyi Gorge cross-section, and also provides the basis for decision on risk control of groundwater exploitation.
\end{abstract}

Key words Zhangye basin; groundwater exploitation; risk control; numerical simulation

\section{INTRODUCTION}

Zhangye basin, with an area of about $8200 \mathrm{~km}^{2}$, is located in the middle reaches of Heihe River basin, Hexi Corridor, North-western China's Gansu Province. It is not only the region which has the highest degree and largest amount of water resource utilization, but also the key area for control of the water-cycle evolution in Heihe River basin. The risk of groundwater exploitation is that the use of regional water resources is not reasonable; it is clear that the surface water resource utilization is saturated, but groundwater resource utilization still has potential (Su Jianping, 2005). Especially in the fine soil plain of the middle reaches and along the two banks of Heihe River, groundwater table depth is less than $5 \mathrm{~m}$ and thickness of the aquifer is big; therefore the amount of groundwater resource is rich.

\section{METHODS}

\section{Groundwater exploitation risk evaluation}

The risk evaluation model for groundwater exploitation of the main irrigation areas in Zhangye basin was established and its structure is shown in Fig. 1. Firstly, to convert the original index value of membership function to a mutation series of 0 to 1 in accordance with the evaluation steps. Then to make comprehensive calculations from the single index layer to the target layer using normalized formula. Taking a reference from the division of flood risk, the groundwater exploitation risk value was classified as in Table 1 (Ye Xueyan, 2006). The assessment results showed that the risk values of groundwater exploitation in each irrigation region within the groundwater system in Zhangye basin were between 0.6257 and 0.8339 , which belonged to the moderate risk category $(0.5-0.85)$ according to the grade criteria of risk category.

\section{Groundwater numerical simulation}

The very thick and loose Quaternary sediments accumulated in Zhangye basin are the natural place for groundwater storage. The Quaternary aquifer is a continuous, unified and mutually superimposed complex of water-bearing rock series (Liu Shaoyu et al., 2002; Yang Lingyuan and Wang Genxu, 2005). Its transverse is limited by the basin boundary and the mountains around basin are natural hydrological boundary. The conceptual hydrogeological model considers the 


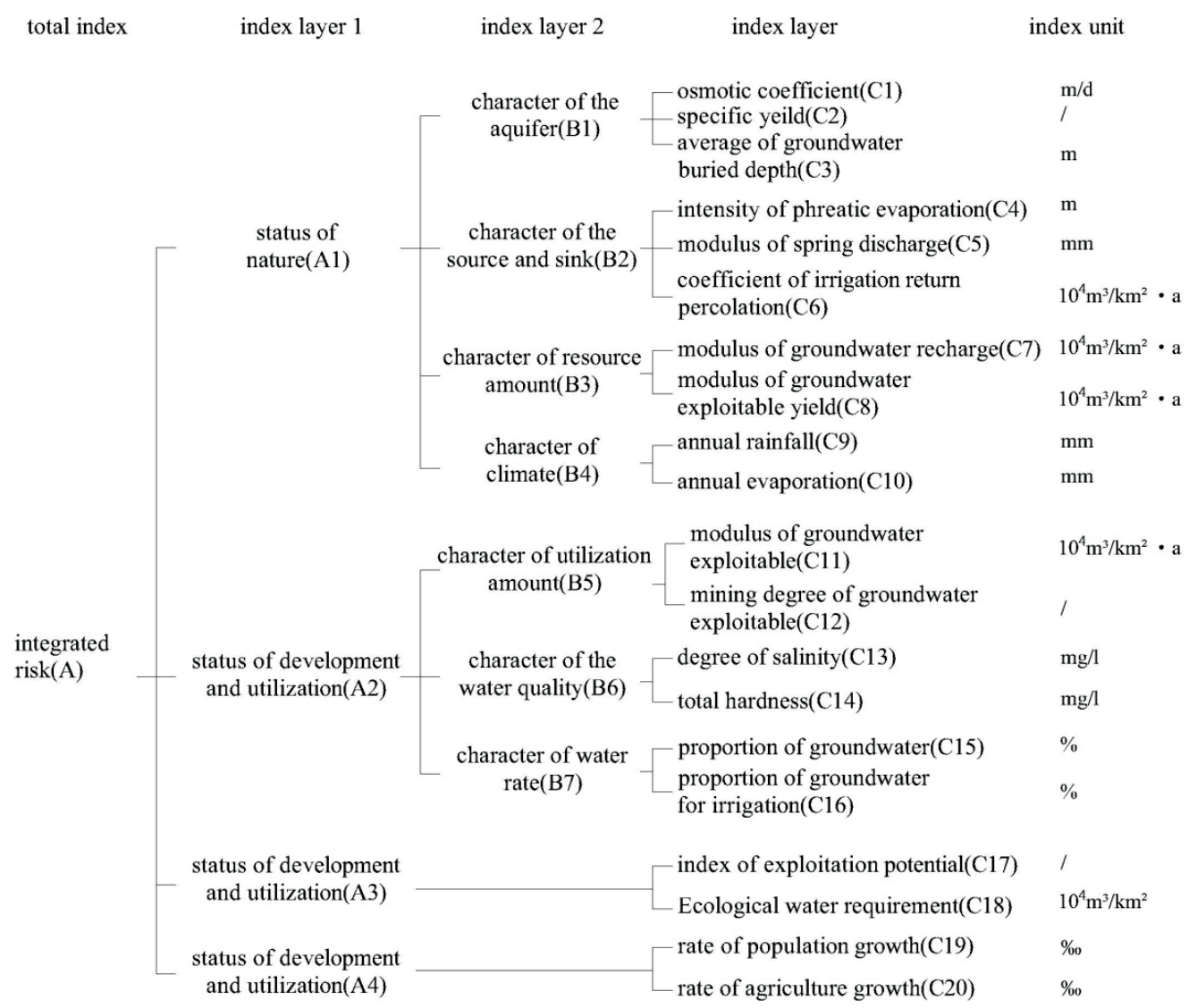

Fig. 1 Structure of the index system of groundwater exploitation risk evaluation in the main irrigation areas in Zhangye basin.

Table 1 The risk rating of groundwater exploitation.

\begin{tabular}{llllll}
\hline Rate & Micro-risk & Mild-risk & Moderate-risk & Severe-risk & Extra severe \\
\hline Risk value & $\mathrm{R}<0.30$ & $0.30<\mathrm{R} \leqslant 0.50$ & $0.50<\mathrm{R} \leqslant 0.85$ & $0.85<\mathrm{R} \leqslant 0.95$ & $\mathrm{R}>0.95$ \\
\hline
\end{tabular}

aquifers in Zhangye basin as a single horizontal aquifer with unsteady two-dimensional flow and a nearly impermeable base. The groundwater movement can be described by Darcy's law.

The vertical boundary is separated as the bottom boundary and top boundary of regional aquifer system. The Quaternary aquifer floor is largely mudstone and sandy mudstone of Jurassic and Tertiary age. Locally the geology is Sinian Erathem marble with little water, which can be regarded as the unified water-resisting floor of basin aquifer system. The top boundary is air-soil interface, and the unsaturated zone and saturated zone are considered as a single entity. This interface is the link between meteoric water, surface water and groundwater.

Zhangye basin has the structure of an intermontane fault. The mountains around basin are natural horizontal boundary and the western part is Qingshui-Yanchi basin. In natural conditions, the two parts have no hydraulic relation, so it can be considered as zero flow boundary. The piedmont of northern low mountain region has few gully undercurrent and can be considered as a zero flow boundary. The southern piedmont is an impulse boundary; the flow includes gully undercurrent and lateral seepage in the deep piedmont. The eastern boundary is an impulse boundary. The hydrogeological model of Zhangye basin is shown as Fig. 2.

\section{Data processing of the source and sink}

The groundwater recharge includes river flow infiltration, canal system water infiltration, irrigation water infiltration and precipitation infiltration etc. The discharge includes spring water 
spillage, outflow to the river from groundwater, evaporation of unconfined groundwater, vegetation transpiration and artificial exploitation. Among them, river flow infiltration, canal system water infiltration, irrigation water infiltration, spring water spillage and artificial exploitation are main processes.

The hydrogeological parameters, such as source and sink parameters selected in this study are cited from the report titled Research on the Rational Exploration and Utilization of Groundwater Resources in the Middle Reaches of Heihe River (No. 2 Team of Hydrogeology and Engineering Geology of Gansu Provincial Bureau of Geology and Mineral Resources, 1990). The water balance was mainly calculated according to the references (Su Jianping, 2005; Wen Xiaohu, 2005; Shen Yuanyuan, 2006).

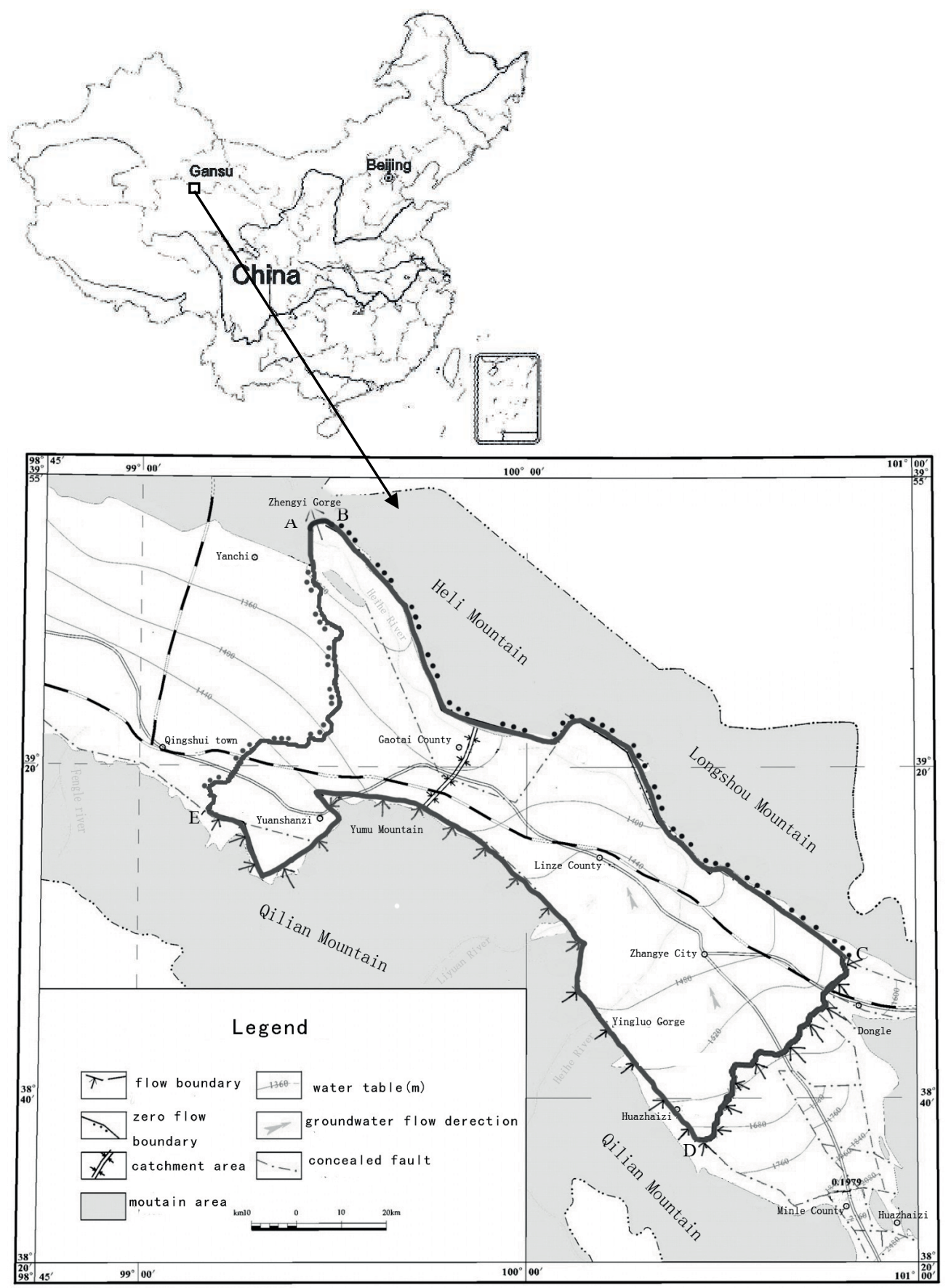

Fig. 2 Hydrogeological model of Zhangye basin and the boundary conditions setting. 


\section{Numerical model of groundwater flow system}

The method of unsteady two-dimensional flow movement was used to the numerical simulation of groundwater flow in Zhangye basin. The initial unconfined groundwater flow field was determined by water table data interpolation from 67 observation wells in January 2005. The transmissibility is between 500 and $14000 \mathrm{~m}^{2} \mathrm{~d}^{-1}$ and the specific yield is 0.08 to 0.2 (Ding Hongwei and Zhang Ju, 2002). The numerical simulation was processed by running MODFLOW software.

According to the conceptual hydrogeological model of Zhangye basin, the simulation area was separated into $1000 \mathrm{~m} \times 1000 \mathrm{~m}$ grid as one unit with the discrete method of equal interval finite-difference. The number of effective units in calculating area is 5511, and the time step is one month. The simulation period is from January to December 2005. The model identification period is from January to June and validation period is from July to December.

\section{RESULTS}

\section{Identification and validation of model}

The model was identified and validated with measured data from January to December 2005. The number of nodes which the fitting error of simulated and measured values of water table was less than $0.5 \mathrm{~m}$ accounted for more than $75 \%$ of the total. It showed that the conceptual hydrogeological framework is useful and reasonable for this study. The model can be used for the dynamic numerical simulation and prediction of groundwater flow system in the study area. Parts of the fitting curves of simulated and measured values of water table are shown in Fig. 3.
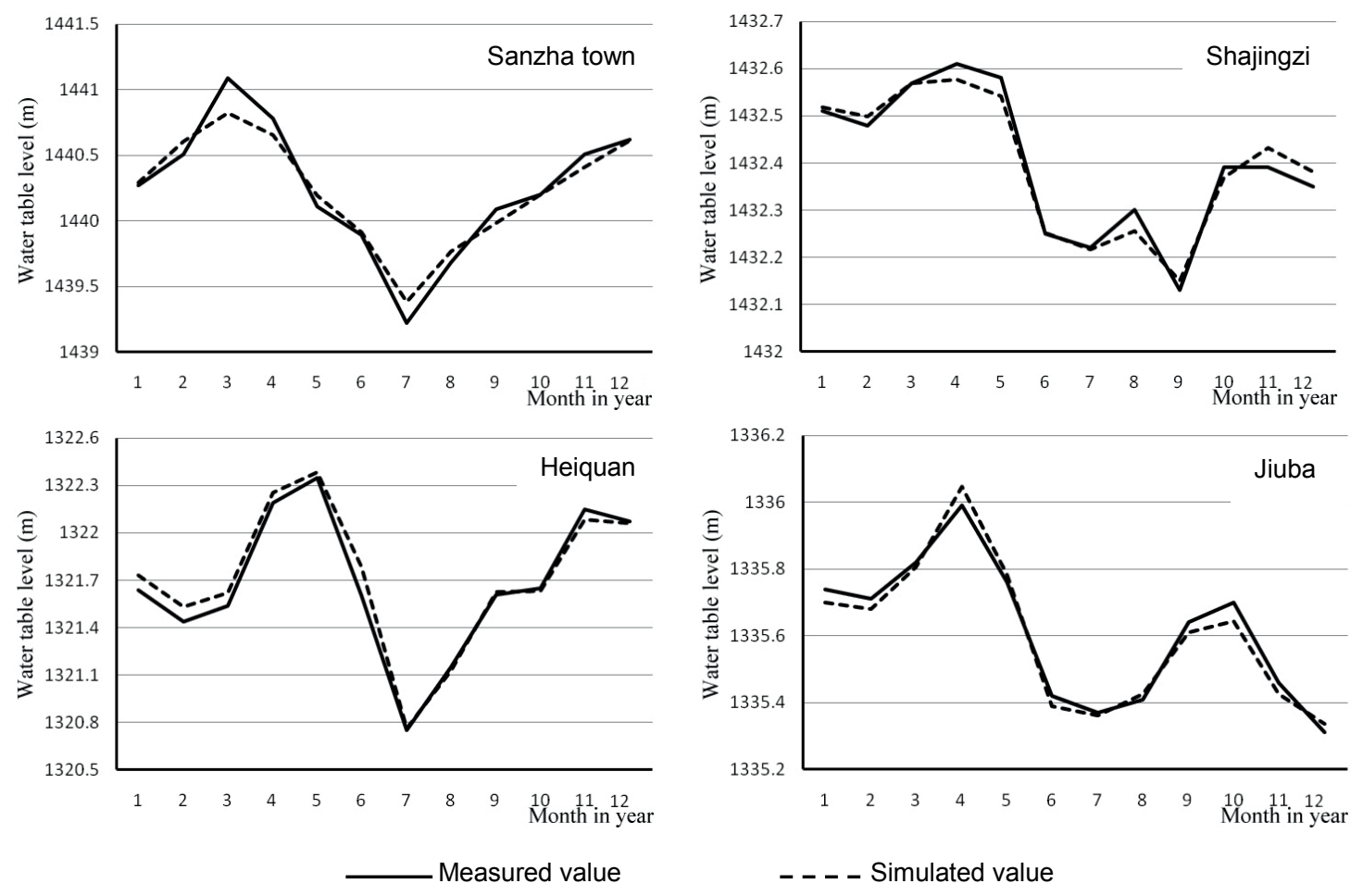

Fig. 3 Fitting curves of simulated and measured values of water table.

For many years, excessive exploitation of surface water in Zhangye basin has led to the problem of continual decrease of annual runoff at Zhengyi Gorge section in Heihe River. If the unreasonable exploitation continues, the amount of groundwater recharge will increase in Zhangye basin, and water table will continuously rise. It will be difficult to maintain temporal and appropriate water supply for Zhengyi Gorge section. The pattern of optimal water resources allocation should be made, and increase the groundwater ratio of total water consumption to 
replace surface water in order to effectively control the risks of groundwater exploitation in Zhangye basin.

\section{Simulation and forecast of groundwater under the planning exploitation conditions}

According to the analysis of groundwater exploitation in Heihe River basin cited from the Report of Groundwater Investigation in Hexi Corridor (Geological Survey Bureau of Gansu, 2002), with statistics data based on the irrigation area in Zhangye basin, it has shown that Yingke, Xijun, Yanuan, Liaoquan are great potential exploitation areas; the increase amount of groundwater exploitation is $6449 \times 10^{4} \mathrm{~m}^{3}$ in Yingke; Shigangduntan, Liyuanhe, Banqiao are moderate potential areas; Anyangtan and Shangsan are less potential areas; Daman, Shahe are balanced areas of exploitation and recharge; Luocheng, Pingchuan, Youlian and Liuba are seriously insufficient potential areas which need total amount of $6824 \times 10^{4} \mathrm{~m}^{3}$ to reduce. According to the planned exploitation amount of groundwater (Geological Survey Bureau of Gansu, 2002), the water balance results calculated by running MODFLOW software are shown in Table 2.

Table 2 The calculated results of water balance in current year and 5 years later by running of the model.

\begin{tabular}{lcrr}
\hline Item & Current year & 5 years later & Change value \\
\hline Total recharge $\left(10^{4} \mathrm{~m}^{3}\right)$ & 112510 & 105699 & -6811 \\
Lateral recharge $\left(10^{4} \mathrm{~m}^{3}\right)$ & 16411 & 16814 & 403 \\
Vertical recharge $\left(10^{4} \mathrm{~m}^{3}\right)$ & 64649 & 54871 & -9778 \\
River recharge $\left(10^{4} \mathrm{~m}^{3}\right)$ & 31450 & 34014 & 2564 \\
Total discharge $\left(10^{4} \mathrm{~m}^{3}\right)$ & 129328 & 123122 & -6206 \\
Exploitation $\left(10^{4} \mathrm{~m}^{3}\right)$ & 29100 & 36700 & 7600 \\
Spring spillage $\left(10^{4} \mathrm{~m}^{3}\right)$ & 56448 & 51245 & -5203 \\
Evaporation $\left(10^{4} \mathrm{~m}^{3}\right)$ & 28924 & 20683 & -8241 \\
River discharge $\left(10^{4} \mathrm{~m}^{3}\right)$ & 11206 & 10845 & -361 \\
Lateral discharge $\left(10^{4} \mathrm{~m}^{3}\right)$ & 3650 & 3649 & -1 \\
\hline
\end{tabular}

Comparing the results in Table 2 shows that the increase of groundwater exploitation amount causes the falling of water table. The amount of annual spring discharge changes from $56448 \times$ $10^{4} \mathrm{~m}^{3}$ to $51245 \times 10^{4} \mathrm{~m}^{3}$, reduction of $9.2 \%$. The annual evaporation of unconfined groundwater decreases by $28.5 \%$ from 28924 to $20683 \times 10^{4} \mathrm{~m}^{3}$. The increase of groundwater exploitation amount is beneficial to reduce evaporation of unconfined groundwater.

Through increasing the amount of groundwater exploitation and reducing that of irrigation extracting surface water, it can displace surface water to supply water for ecological environment and industry in the lower reaches. Meanwhile, the falling of water table will increase the groundwater recharge from surface water; this phenomenon is more obvious in groundwater exploitation along the bank of River.

Supposing that the standard of irrigation water use in field was unchanged, the reduced amount of surface water should be calculated as the following equation:

$$
\left\{\begin{array}{l}
Q_{s, f}+Q_{g, f}=Q_{f} \\
Q_{s, f}=Q_{s, q} \cdot \eta_{s} \\
Q_{g, f}=Q_{g, q} \cdot \eta_{g}
\end{array}\right.
$$

Where $Q_{f}$ is the total amount of irrigation water use in field, its calculated value is $106200 \times$ $10^{4} \mathrm{~m}^{3} ; Q_{s, f}, Q_{s, q}$ are respectively the amount of surface water into field and that of the irrigation water extraction; the present surface water extraction is $159700 \times 10^{4} \mathrm{~m}^{3} ; Q_{g}, f, Q_{g, q}$ are respectively the amount of groundwater into field and that of groundwater exploitation; the amount of present and planned groundwater exploitation are respectively $29100 \times 10^{4} \mathrm{~m}^{3}$ and $36700 \times 10^{4}$ $\mathrm{m}^{3} ; \eta_{s}, \eta_{g}$ are respectively the water efficiency in canal system of surface water and groundwater, 0.65 and 0.85 . 
Accordingly, the amount of annual irrigation extracting surface water is $149600 \times 10^{4} \mathrm{~m}^{3}$ under the condition of planned groundwater exploitation; $10100 \times 10^{4} \mathrm{~m}^{3}$ will be saved annually. Deducting the amount of river flow recharge to groundwater, $2564 \times 10^{4} \mathrm{~m}^{3}$ annually, and the annual river runoff can increase $7536 \times 10^{4} \mathrm{~m}^{3}$.

\section{CONCLUSIONS}

(a) An index system model of groundwater exploitation risk evaluation of the main irrigation areas in Zhangye basin was established. The risk values of groundwater exploitation in each irrigation region within groundwater system in Zhangye basin were between 0.6257 and 0.8339 , which belonged to the moderate risk $(0.5-0.85)$ according to the grade criteria of risk category.

(b) The fitting errors of water table conform to the accuracy requirements. The model of groundwater numerical simulation was reasonable, and it can be used for the dynamic numerical simulation and prediction of groundwater in study area.

(c) The increasing of groundwater exploitation amount based on planning is effective for the control of groundwater exploitation risk. The annual river runoff will increase after deducting the increased amount of river flow recharge to groundwater. So the let-down flow from Zhengyi Gorge is effectively guaranteed.

Acknowledgements This study is supported by the Lanzhou University Fundamental Research Funds for the Central Universities, "Rivers in the middle reaches of Heihe River basin - process of aquifer transformation (lzujbky-2010-181)" and the Open Funds of the Key Laboratory of Inland River Ecohydrology of Chinese Academy of Sciences.

\section{REFERENCES}

Ding Hongwei and Zhang Ju (2002) The problem of environment caused by groundwater level continuous decline in the inland basins of arid area, Northwest China: an example in middle reaches of Heihe River basin. Hydrogeology \& Engineering Geology 29(3), 71-75.

Geological Survey Bureau of Gansu (2002) Report of groundwater investigation in Hexi Corridor. Gansu, China.

Liu Shaoyu et al. (2002) Resource environmental effect of groundwater system and water resource exploitation in the basin of the middle and lower of Heihe River. Geography and Territorial Research 18(4), 90-96.

No. 2 Team of Hydrogeology and Engineering Geology of Gansu Provincial Bureau of Geology and Mineral Resources (1990) Research on the rational exploration and utilization of groundwater resources in the middle reaches of Heihe River. Gansu, China.

Shen Yuanyuan (2006) Numerical simulation model of groundwater in Heihe River and the application research on water Management. MSc Thesis, Jilin University, Changchun, Jilin, China.

$\mathrm{Su}$ Jianping (2005) Groundwater simulation and sustainable utilization of water resources in Zhangye basin of the middle reaches of Heihe River. PhD Thesis, CAREERI, CAS, Lanzhou, Gansu, China.

Wen Xiaohu (2005) Research of groundwater salinization characteristic and salt transportation simulation in Zhangye basin of the middle reaches of Heihe River. PhD Thesis, CAREERI, CAS, Lanzhou, Gansu, China.

Yang Lingyuan and Wang Genxu (2005) Variations of groundwater in Zhangye basin of the middle reaches of the Heihe River in recent two decades. Journal of Glaciology and Geocryology 27(2), 290-296.

Ye Xueyan (2006) Study on evaluation and regulation of groundwater pumping risk in perched section of down-Yellow River. PhD Thesis, Jilin University, Changchun, Jilin, China. 